RACIC 5 (2 (2020)
JUIVERSITAS
ABDURRAB

\title{
STUDI ANALISIS DAMPAK LALU LINTAS AKIBAT PEMBANGUNAN KAMPUS II INSTITUT TEKNOLOGI PADANG (STUDI KASUS JALAN DPR AIR PACAH KOTA PADANG)
}

\author{
Wilton Wahab ${ }^{1}$ Afrizal Putra Prices ${ }^{2}$ Angelalia Roza $^{3}$ \\ ${ }^{1,3}$ Dosen Program Studi Teknik Sipil, Fakultas Teknik, Institut Teknologi Padang \\ ${ }^{2}$ MahasiswaProgram Studi Teknik Sipil, Fakultas Teknik, Institut Teknologi Padang \\ Jl. Gajah Mada, Kec. Nanggalo, Kota Padang, Sumatera Barat 25173 \\ email :wahab.wilton@yahoo.com \\ email : afrizalputraprices@gmail.com \\ email : angelaliaroza@gmail.com
}

\begin{tabular}{l}
\hline Info Artikel \\
\hline Sejarah Artikel: \\
Diterima November 2020 \\
Disetujui November 2020 \\
Dipublikasikan Desember \\
2020
\end{tabular}

Keywords : andalalin, volume Lalulintas, kinerja ruas jalan

\section{Abstrak}

Institut Teknologi Padang (ITP) merupakan kampus teknik tertua di Provinsi Sumatera Barat yang terletak di dua lokasi yakni di Jalan Gajah Mada (Kampus I) dan di Jalan DPR (Kampus II). Saat ini ITP sedang melakukan pembangunan Kampus II pada lahan seluas $\pm 1,5 \mathrm{HA}$. Pembangunan Kampus II ini berpotensi meningkatkan volume lalulintas. Meningkatnya volume lalulintas akan berpengaruh terhadap kinerja jalan sehingga perlu kajian lebih lanjut. Tujuan penelitian ini adalah untuk menganalisis seberapa besar dampak lalulintas akibat pembangunan kampus II terhadap kinerja ruas jalan. Analisis yang dilakukan meliputi analisis kinerja ruas jalan, pada kondisi pra, masa, dan pasca konstruksi; termasuk proyeksi kebutuhan ruang parkir. Hasil penelitian menunjukkan bahwa kinerja ruas jalan DPR pada kondisi pra konstruksi dan masa konstruksi berada pada level B (kinerja baik), namun pada masa pasca konstruksi berada pada level C (kinerja cukup). Sedangkan kinerja ruas jalan Bypass pada kondisi pra konstruksi, masa konstruksi, dan pasca konstruksi berada pada level B (kinerja baik) namun sudah mendekati level C (kinerja cukup).

Kata Kunci: Andalalin, Volume Lalulintas, Kinerja ruas jalan.

\section{Abstract}

Padang Institute of Technology (ITP) is the oldest engineering campus in West Sumatra province, located in two locations, namely Jalan Gajah Mada,(Campus I) and Jalan DPR (Campus II). ITP is currently conducting construction (Campus II) on an area of $\pm 1.5 \mathrm{HA}$. The construction of Campus II potentially to increase the trip number. The rise of the traffic volume affect the road performance so further research is needed. This study aims to analyze the impact of the construction of campus II ITP towards the road performance. The analysis carried out includes the traffic impact analysis during pre- 
construction, the construction and post-construction conditions; as well as projecting the parking space requirenment. The results of this study show that the performance of road sections on Jalan DPR in preconstruction and the construction period are on the level B (good performance). But in the post-construction it will reach the level $C$ (sufficient performance). Meanwhile, the performance of the Bypass road segment duruing all the pre-construction, the construction period, and post-construction are at the level B (good performance), but begin to approach the level C (sufficient performance).

Keywords: reliable, Traffic volume, road performance

(C) 2020 Universitas Abdurrab

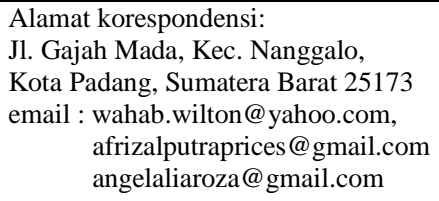

\section{PENDAHULUAN}

Kota Padang merupakan ibu kota provinsi Sumatera Barat dengan jumlah penduduk 950.871 jiwa dengan luas mencapai $694,93 \mathrm{~km}^{2}$ wilayah darat dan $720 \mathrm{~km} 2$ wilayah laut (BPS Kota Padang, 2019). Kota Padang merupakan pusat perekonomian dan pendidikan di Sumatera Barat. Ketersediaan sarana dan prasarana tranportasi yang memadai di Kota Padang, sangat diperlukan dalam upaya pengembangan pusat kegiatan tersebut.

Ruas jalan di Kota Padang yang menjadi kajian pada Penelitian ini adalah Ruas Jalan Bypass dan ruas jalan DPR yang terletak di Kelurahan Air Pacah. Kedua ruas jalan tersebut merupakan jalur akses keluar masuk Kampus II Institut Teknologi Padang. Saat ini sedang berlangsung pembangunan Gedung Fakultas Vokasi (5 lantai) seluas $6.275 \mathrm{~m}^{2}$ dan Gedung Rusunawa (3 lantai) seluas $1.092 \mathrm{~m}^{2}$. Pembangunan kampus II ITP tersebut tentu berdampak pada pergerakan orang dan/atau barang di kawasan ini. Sehingga diduga kinerja jaringan jalan Bypass dan ruas jalan DPR berpotensi menurun. Penelitian ini bertujuan untuk menganalisis dampak lalulintas akibat pembangunan Kampus II ITP saat pra konstruksi; masa konstruksi; dan pasca konstruksi, melalui pendekatan analisis bangkitan dan tarikan, analisis kinerja ruas jalan, dan analisis penanganan dampak lalulintas.

\section{STUDI LITERATUR}

Analisis dampak lalulintas pada dasarnya merupakan analisis pengaruh pengembangan tata guna lahan terhadap sistem pergerakan arus lalu-lintas disekitarnya yang diakibatkan peralihan lalu intas, akibat kendaraan keluar masuk, dan akibat bangkitan lalu-lintas (Tamin 
2000; Syafridho, A.Y., 2017). Diperlukan studi khusus terkait analisis dampak lalulintas sebelum, saat dan setelah penggunaan lahan untuk pembangunan fasilitas gedung dilakukan dalam rangka mengantisipasi dampak negatif terhadap sistem transportasi kota.

PP No.32 Tahun 2011 tentang Manajemen dan Rekayasa, Analisa Dampak, serta Manajemen Kebutuhan Lalulintas, menjelaskan bahwa setiap rencana pembangunan pusat kegiatan, pemukiman, dan infrastruktur yang akan menimbulkan gangguan kaamanan, keselamatan, ketertiban, dan kelancaran lalulintas dan angkutan jalan wajib dilakukan analisis dampak lalu lintas.

Menurut The Institution of Highways and Transportation (1994), besarnya dampak kegiatan terhadap lalu lintas dipengaruhi oleh jenis tarikan perjalanan pusat kegiatan, kompetisi beberapa pusat kegiatan yang berdekatan, daya tarik suatu pusat kegiatan, prasarana jalan di sekitar pusat kegiatan, bangkitan atau tarikan perjalanannya, dan tingkat kelancaran lalu lintas pada jaringan jalan yang ada. Maka ketika sistem guna lahan berinteraksi dengan lalulintas, ada 5 (lima) faktor penting yang perlu diperhitungkan; diantaranya (1) Faktor bangkitan atau tarikan perjalanan, yang dipengaruhi oleh tipe dan kelas peruntukan, intensitas serta lokasi bangkitan; (2) Faktor kinerja jaringan ruas jalan, yang mencakup kinerja ruas jalan dan persimpangan; (3) Faktor akses, berkenaan dengan jumlah dan lokasi akses; (4) Faktor ruang parkir; (5) Faktor lingkungan, khususnya berkenaan dengan dampak polusi dan kebisingan.

Identifikasi dampak lalu lintas pada beberapa proyek konstruksi pernah dilaporkan peneliti sebelumnya (Jamani, W. Y., Hasyim, \& Rohani, 2016; Styawan, A., dkk, 2019; Rahman, A., dkk, 2018; Rantung, T.,et.al.,2015) . Secara spesifik Jamani, W. Y., Hasyim, \& Rohani (2016) memprediksi pengaruh pembangunan Rumah Sakit Graha Ultima Medika pasca konstruksi yakni setelah rumah sakit beroperasi Pendekatan analisis dilakukan dengan menghitung pembebanan lalu lintas dan kinerja ruas jalan melalui perhitungan derajat Kejenuhan/DS), dan sirkulasi pergerakan. Hasil penelitian tersebut menunjukkan dampak lalulintas timbul bernilai kecil, sehingga tidak diperlukan solusidan penanganan khusus, melainkan perlu dilakukan pengaturan lalulintas untuk meminimalisir gangguan arus di Jl. Majapahit (Jamani, W. Y., Hasyim, \& Rohani, 2016) .

Penelitian lainnya dilakukan pada proyek Revitalisasi Pasar Sumber gempol Kabupaten Tulungagung (Styawan, A., dkk, 2019). Analisa dampak lingkungan menghasilkan rekomendasi teknis terkait ruang parkir. Diberikan saran kepada pihak pengembang pasar agar menyediakan luas parkir minimal 144,3 $\mathrm{m}^{2}$ (untuk roda dua) dan 1203,13 $\mathrm{m}^{2}$ (untuk roda empat).

Dalam memprediksi tarikan perjalanan yang terjadi akibat pembangunan suatu kawasan, pendekatan analisis dapat dilakukan dengan menganalisis model tarikan pergerakan 
dan kinerja jaringan jalan yang terpengaruh langsung oleh aktifitas kegiatan. Hal tersebut dilakukan pada analisis dampak lingkungan khususnya terhadap kinerja lalu lintas pada pembangunan Lippo Plaza (Rantung, T. et.al, 2015).

Dampak Pembangunan kawasan dapat dilakukan dengan mempertimbangkan kondisi eksisting kondisi 2 tahun masa pembangunan (2020), dan 5 tahun pasca beroperasi (2025) baik dengan pengembangan kawasan maupun tanpa pengembangan Kawasan. Pendekatan analisis tersebut dilakukan pada pengembangan kawasan Apartemen Puncak Dharmahusada Surabaya (Rahman, A., dkk, 2018). Hasil analisis dampak lingkungan terkait perbaikan kinerja persimpangan diberikan berupa rekomendasi perubahan fase dan waktu hijau pada simpang bersinyal Jl. Dr. Ir. Soekarno - Jl. Mulyorejo dan simpang bersinyal Jl. Dr. Ir. Soekarno - Jl. Kenjeran.

Dalam analisa dampak lalu lintas, diperlukan pertimbangan terhadap tarikan perjalanan dan kinerja lalu lintas pada ruas jalan yang diperkirakan terpengaruh (Firdaus, O., 2017). Langkah tersebut perlu diawali dengan pengamatan terhadap kapasitas jalan dikawasan kajian. Kapasitas jalan adalah jumlah kendaraan maksimum yang dapat melewati suatu jalan pada jalur jalan selama 1 jam dengan kondisi serta arus lalulintas tertentu. Besarnya kapasitas suatu ruas jalan perkotaan (MKJI 1997) dapat dihitung dengan persamaan (1) berikut ini :

$\mathrm{C}=\mathrm{Co} \times \mathrm{FCw} \times$ FCsp $\mathrm{x}$ FCsf $\mathrm{x}$ FCcs

Sehingga formulasi (Persamaan 1) pada perhitungan nilai C (kapasitas ruas jalan dalam satuan smp/jam) harus disesuaikan dengan nilai Kapasitas dasar (Co) dan kapasitas segmen jalan untuk kondisi tertentu sesuai kondisi geometrik, pola arus lalulintas, dan faktor lingkungan. Secara tersebut variabel yang dimaksuid adalah $\mathrm{FCw}$ yang merupakan faktor penyesuaian lebar jalur lalulintas; FCsp yang merupakan faktor penyesuaian akibat pemisahan arah lalu lintas yang terjadi pada jalan dua arah tak terbagi. Berikutnya FCsf yang merupakan faktor penyesuaian hambatan samping), yang mewakili nilai hambatan arus lalu lintas akibat jumlah kendaraan yang bergerak lambat (Wahab, W., 2015). Serta, FCcs yang merupakan faktor terkait penyesuaian ukuran kota. Ketika kondisi ideal terpenuhi, maka seluruh faktor penyesuaian bernilai 1,0 sehingga otomatis kapasitas tersebut bernilai sama dengan kapasitas dasar (Co).

Mengacu pada Manual Kapasitas Jalan Indonesia (1997) nilai ekivalensi untuk Satuan Mobil Penumpang (smp) berbagai jenis kendaraan dapat dihitung berdasarkan faktor ekivalen mobil penumpang (emp). Pada tahap analisis lanjutan setelah perhitungan kapasitas, perlu dihitung nilai Derajat Kejenuhan (DS) adalah rasio arus lalulintas terhadap kapasitas, yang 
digunakan sebagai faktor utama dalam penentuan tingkat kinerja ruas jalan dan/atau persimpangan. Nilai DS menunjukkan apakah segmen jalan tersebut mempunyai masalah kapasitas atau tidak. Rumusan untuk menghitung nilai, sebagai berikut (MKJI, 1997) :

$\mathrm{DS}=\mathrm{Q} / \mathrm{C}$

dimana DS merupakan Derajat kejenuhan; Q merupakan Arus maksimum (smp/jam) dan C merupakan Kapasitas (smp/jam). Kinerja pelayanan lalu lintas akan semakin buruk ketika nilai perbandingan tersebut makin besar, dan berdampak pada kecepatan operasional kendaraan yang merupakan bentuk fungsi dari besaran waktu tempuh kendaraan. MKJI 199 mengkalsifikasikan Interval Nilai DS mengklasifikasikan kedalam 6 tingkatan (Bere, E., 2015). Keenam Tingkat pelayanan tersebut dapat dilihat pada Tabel 1 berikut :

Tabel 1 : Batas Nilai Tingkat Pelayanan Ruas Jalan (DS)

\begin{tabular}{|c|l|c|}
\hline $\begin{array}{c}\text { Tingkat } \\
\text { Pelayanan }\end{array}$ & \multicolumn{1}{|c|}{ Karakteristik } & $\begin{array}{c}\text { Batas Lingkup } \\
\text { DS }\end{array}$ \\
\hline A & $\begin{array}{l}\text { Kondisi arus bebas dengan kecepatan tinggi, pengemudi } \\
\text { dapat memilih kecepatan yang di inginkan tanpa hambatan }\end{array}$ & $0,00-0,20$ \\
\hline B & $\begin{array}{l}\text { Arus stabil, tetapi kecepatan operasi mulai dibatasi oleh } \\
\text { kondisi lalu lintas, pengemudi memiliki kebebasan yang } \\
\text { cukup untuk memilih kecepatan }\end{array}$ & $0,20-0,44$ \\
\hline C & $\begin{array}{l}\text { Arus stabil, tetapi kecepatan dan gerak kendaraan } \\
\text { dikendalikan, pengemudi dibatasi dalam memilih kecepatan }\end{array}$ & $0,45-0,74$ \\
\hline D & $\begin{array}{l}\text { Arus mendekati tidak stabil, kecepatan masih dikendalikan, } \\
\text { V/C masih dapat ditolerir }\end{array}$ & $0,75-0,84$ \\
\hline E & $\begin{array}{l}\text { Volume lalu lintas mendakati/berada pada kapasitas, arus } \\
\text { tidak stabil, kecepatan terkadang terhenti }\end{array}$ & $0,85-1,00$ \\
\hline F & $\begin{array}{l}\text { Arus yang dipaksakan atau macet, kecepatan rendah, volume } \\
\text { diatas kapasitas, antrian panjang dan terjadi hambatan besar }\end{array}$ & $>1,00$ \\
\hline
\end{tabular}

Sumber : MKJI 1997

\section{METODOLOGI PENELITIAN}

Agar mendapatkan hasil penelitian yang optimal dan sesuai dengan tujuan penelitian yang diharapkan, maka metodologi penelitian harus dirancang sedemikian rupa. Adapun metodologi penelitian yang dirancang terdiri dari beberapa tahapan, yaitu : tahapan persiapan, tahapan pengumpulan data, tahap pengolahan dan analisis data, serta kesimpulan (Wahab, W.,\& Adrian, W., 2018). Kegiatan pada tahap persiapan berupa : survei pendahuluan (untuk pengambilan data awal), survei data geometrik, mengumpulkan data sekunder, dan mengolah data survei awal. 


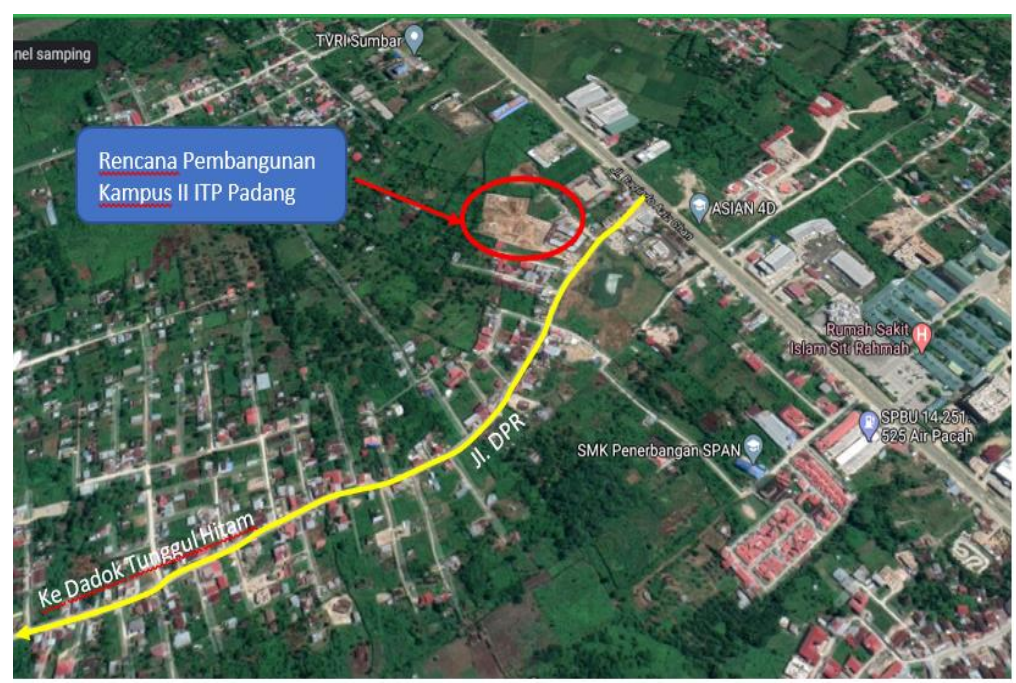

Gambar 1. Lokasi Penelitian

Metode pengumpulan data dilakukan dengan 2 (dua) cara, yaitu melalui survei langsung di lapangan (data primer) dan cara survei instansional (data sekunder). Adapun data-data yang disurvei langsung ke lapangan, berupa : data volume lalulintas, kecepatan kendaraan, geometrik jalan dan persimpangan, pejalan kaki, dan data tarikan perjalanan. Sedangkan data sekunder yang dibutuhkan terdiri dari : peta tata guna lahan, gambar site plan ITP, data sosial ekonomi masyarakat, peta lokasi penelitian, dll. Survei data primer dilakukan 3 (tiga) hari yakni tanggal 01, 02, dan 03 Maret 2020, dari jam 07.00 wib s.d 18.00 wib. Pengambilan data selama tiga hari cukup mewakili kebutuhan data penelitian karena diasumsikan sudah mewakili hari libur dan hari kerja. Sedangkan jam survei selama 12 jam dari 06.00 wib s.d 18.00 wib juga diasumsikan sudah mewakili tentang gambaran arus lalulintas dilokasi.

Metode Analisis data mengacu kepada MKJI 1997; PP Nomor 32 tahun 2011 tentang Manajemen dan Rekayasa, Analisa Dampak, serta Manajemen Kebutuhan Lalulintas; dan sumber rujukan lainnya yang relevan.

\section{HASIL DAN PEMBAHASAN}

Data komposisi kendaraan hasil survei ditampilkan pada Tabel 2 dan Tabel 3. Sedangkan pada Gambar 3 dan 4 diperlihatkan persentase komposisi kendaraan.

Tabel 2 : Komposisi Kendaraan di Ruas Jalan DPR (Dadok Tunggul Hitam) (kend/hari)

\begin{tabular}{|c|c|c|c|c|}
\hline \multicolumn{2}{|c|}{ Jenis Kendaraan } & Bypass - Dadok & Dadok-Bypass & Jumlah \\
\hline 1 & Sepeda Motor & 4.302 & 4.071 & 8.373 \\
\hline 2 & Mobil Pribadi & 819 & 844 & 1.663 \\
\hline 3 & Pick Up & 187 & 165 & 352 \\
\hline 4 & Truk Sedang 2 as & 164 & 170 & 334 \\
\hline
\end{tabular}


Wilton Wahab, Afrizal Putra Prices, Angelalia Roza / Jurnal Rab Contruction Research 5 (2) (2020)

\begin{tabular}{|c|c|c|c|c|}
\hline 5 & Truk Besar 3 as & 14 & 6 & 20 \\
\hline 6 & Angkot/Mikrolet & 8 & 10 & 18 \\
\hline 7 & Bus Besar & 4 & 5 & 9 \\
\hline 8 & Bus Sedang & 3 & 1 & 4 \\
\hline & JUMLAH (unit) & $\mathbf{5 . 5 0 1}$ & $\mathbf{5 . 2 7 2}$ & $\mathbf{1 0 . 7 7 3}$ \\
\hline
\end{tabular}

Tabel 3 : Komposisi Kendaraan di Ruas Jalan Bypass (kend/hari)

\begin{tabular}{|c|l|c|c|c|}
\hline \multicolumn{2}{|c|}{ Jenis Kendaraan } & $\begin{array}{c}\text { Teluk Bayur- } \\
\text { Bandara }\end{array}$ & $\begin{array}{c}\text { Bandara - } \\
\text { Teluk Bayur }\end{array}$ & Jumlah \\
\hline $\mathbf{1}$ & Sepeda Motor & 11.085 & 9.948 & 21.033 \\
\hline $\mathbf{2}$ & Mobil Pribadi & 4.361 & 5.767 & 10.128 \\
\hline $\mathbf{3}$ & Truk Sedang 2 as & 873 & 901 & 1.774 \\
\hline $\mathbf{4}$ & Pick Up & 796 & 925 & 1.721 \\
\hline $\mathbf{5}$ & Truk Besar 3 as & 684 & 688 & 1.372 \\
\hline $\mathbf{6}$ & Bus Kecil & 36 & 81 & 117 \\
\hline $\mathbf{7}$ & Bus Sedang & 40 & 64 & 104 \\
\hline $\mathbf{8}$ & Bus Besar & 49 & 40 & 89 \\
\hline $\mathbf{9}$ & Angkot/Mikrolet & 42 & 38 & 80 \\
\hline $\mathbf{1 0}$ & Truk Trailer/Gandeng/ & 22 & 36 & 58 \\
& Kontainer & & & $\mathbf{1 8 . 4 8 8}$ \\
\hline & JUMLAH (unit) & $\mathbf{1 7 . 9 8 8}$ & & $\mathbf{3 6 . 4 7 6}$ \\
\hline
\end{tabular}

\begin{tabular}{|l}
\hline $\mathbf{1 5 , 4 \%}$ \\
\end{tabular}

Gambar 2 : Persentase Komposisi Kendaraan Ruas Jalan DPR (Dadok Tunggul Hitam)

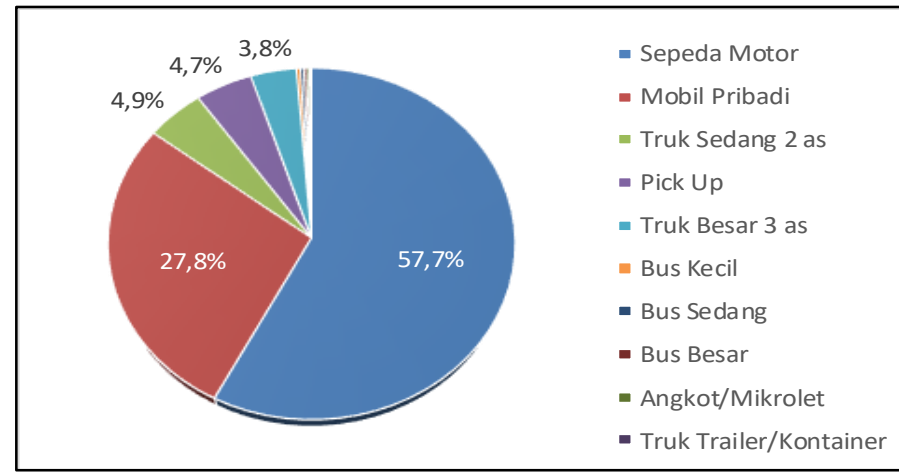

Gambar 3 : Persentase Komposisi Kendaraan Ruas Jalan Bypass.

Selanjutnya, pada gambar 4 dan gambar 5 diperlihatkan grafik fluktuasi jumlah kendaraan perjam berdasarkan hasil perhitungan volume lalulintas dalam satuan smp/jam. 


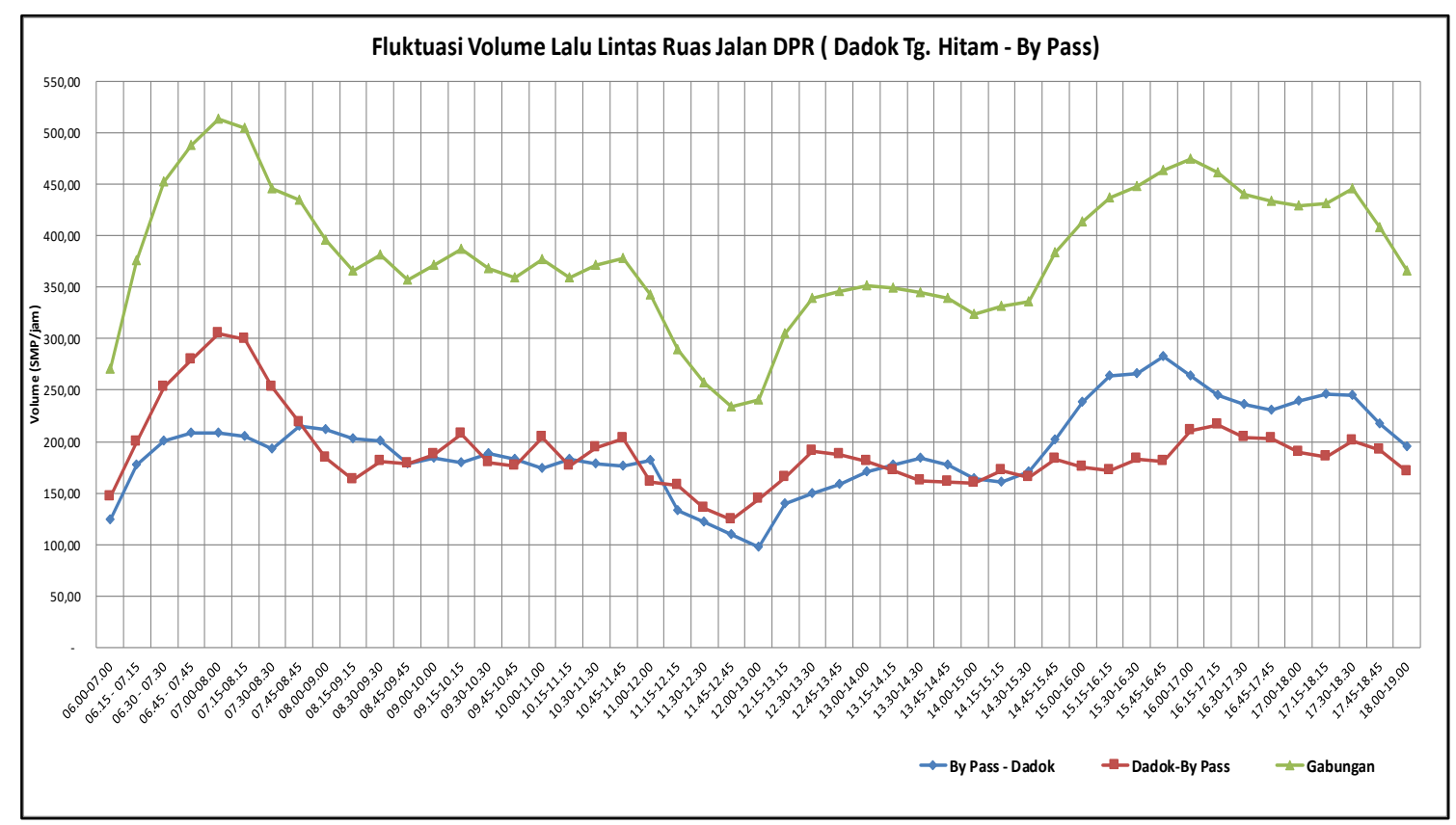

Gambar 4. Grafik Fluktuasi Volume Lalulintas Ruas Jalan DPR (Dadok Tunggul Hitam) (smp/jam)

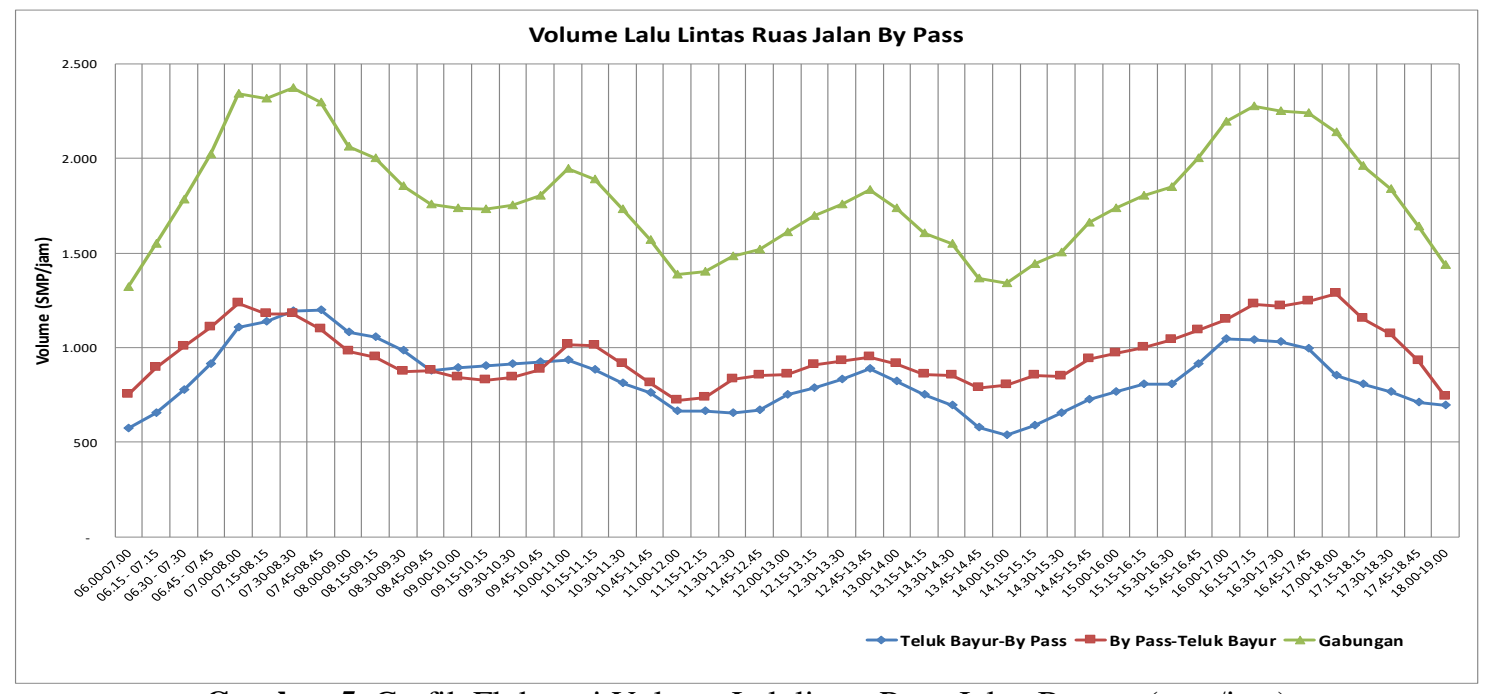

Gambar 5. Grafik Fluktuasi Volume Lalulintas Ruas Jalan Bypass (smp/jam)

Berdasarkan hasil pengolahan data volume lalulintas didapatkan volume lalulintas jam puncak (peak hours) sebagaimana terlihat pada tabel 4 berikut :

Tabel 4: Volume Lalu Lintas Jam Puncak pada hari Kerja (smp/jam)

\begin{tabular}{|c|c|c|c|c|c|}
\hline \multicolumn{2}{|c|}{ Nama Ruas Jalan } & \multirow{2}{*}{ Jam Puncak } & \multicolumn{3}{|c|}{ Volume Lalulintas (smp/jam) } \\
\hline 1 & $\begin{array}{c}\text { DPR (Dadok } \\
\text { Tunggul Hitam) }\end{array}$ & & Bypass - Dadok & Dadok - Bypass & Dua Arah \\
\hline & Pagi & 07:00-08:00 & 208,90 & 305,10 & 514,00 \\
\hline & Siang & 12:00-13:00 & 170,60 & 181,00 & 351,60 \\
\hline & Sore & 16:00-17:00 & 264,40 & 210,80 & 475,20 \\
\hline 2 & Bypass & & Teluk Bayur- & Bandara-Teluk & Dua Arah \\
\hline
\end{tabular}


Wilton Wahab, Afrizal Putra Prices, Angelalia Roza / Jurnal Rab Contruction Research 5 (2) (2020)

\begin{tabular}{ccccc}
\hline Nama Ruas Jalan & Jam Puncak & \multicolumn{3}{c}{ Volume Lalulintas (smp/jam) } \\
\hline \hline & & Bandara & Bayur & \\
\hline Pagi & $07: 30-08: 30$ & $1.192,10$ & $1.180,35$ & $\mathbf{2 . 3 7 2 , 4 5}$ \\
Siang & $12: 45-13: 45$ & 888,55 & 947,55 & $1.836,10$ \\
Sore & $16: 15-17: 15$ & $1.043,75$ & $1.231,65$ & $\mathbf{2 . 2 7 5 , 4 0}$ \\
\hline
\end{tabular}

Sumber : Hasil Perhitungan, 2020

Parkir kendaraan merupakan variabel penting untuk dikaji. Di dalam mengidentifikasi kinerja parkir dapat dilihat pada karakteristik parkir baik akumulasi, volume parkir. Di samping itu Durasi parkir dan Turn Over kendaraan bermotor juga menjadi penting untuk di ketahui. Pada akhirnya dapat juga mengetahui kebutuhan ruang parkir yang disediakan oleh pemakarsa.

Namun dalam analisis dampak lalulintas kampus II ITP Padang ini pengkajian parkir hanya di gunakan untuk mengetahui distribusi perjalanan yang dilakukan mahasiswa diploma III yang nantinya akan kuliah di kampus II ITP Padang itu sendiri. Untuk mengetahui kinerja distribusi perjalanan baik sepeda motor dan mobil di Kampus II ITP dilakukan dengan cara menghitung data parkir di kampus I ITP Padang yang terletak di Jalan Gajah Mada, Kecamatan Nanggalo.

Berdasarkan data survei, menunjukkan bahwa akumulasi parkir sepeda motor tertinggi di areal parkir Kampus II ITP adalah 246 kendaraan, terjadi pada pukul 10.30-11.00 wib. Sedangkan volume terbesar sepeda motor yang masuk areal parkir Kampus II ITP yaitu 897 kendaraan. Gambaran volume kendaraan yang masuk dan keluar akumulasi parkir dan volume parkir sepeda motor dan mobil dapat dilihat pada gambar 6 dan 7 dibawah.

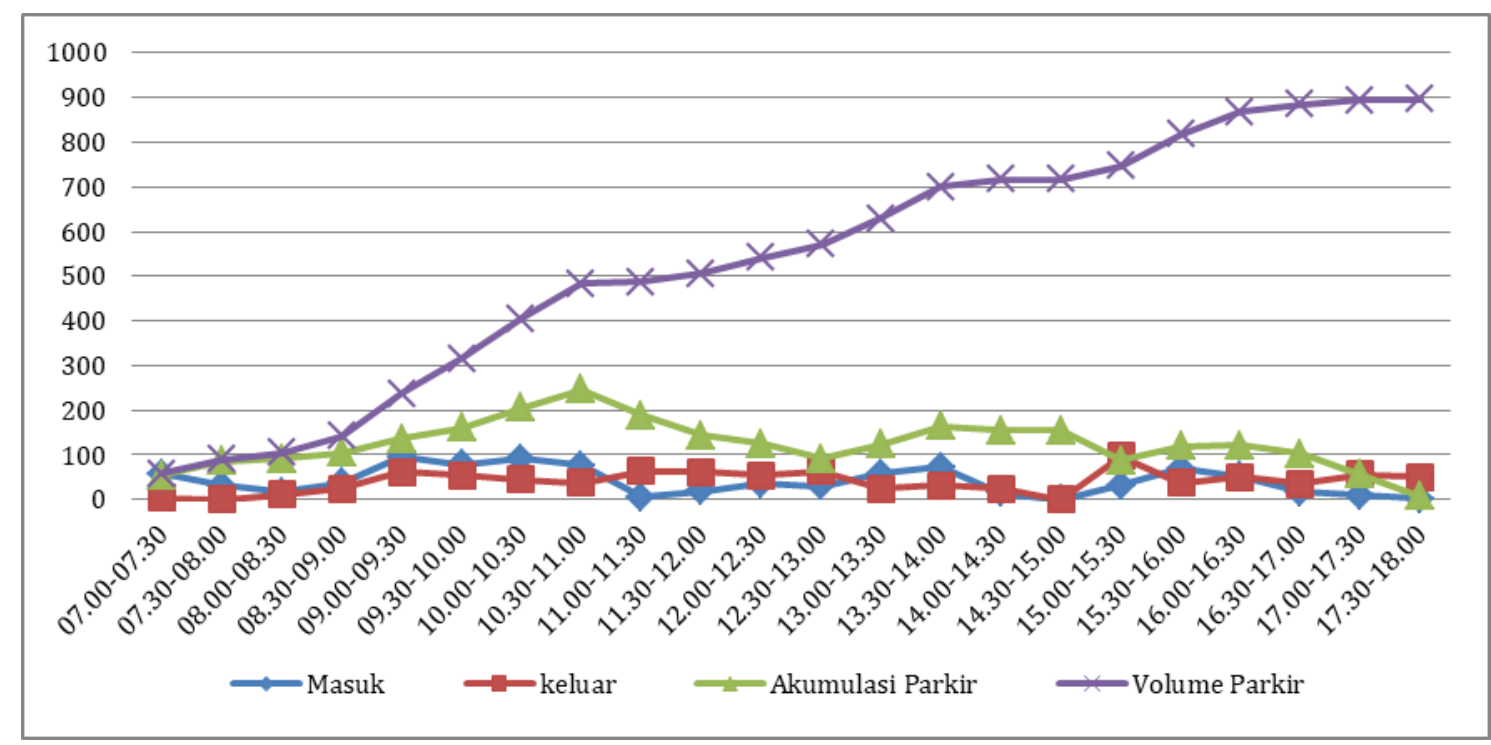

Gambar 6 : GrafikVolume Parkir dan Akumulasi Parkir Sepeda Motor di Areal Parkir Kampus II ITP (Asumsi) 


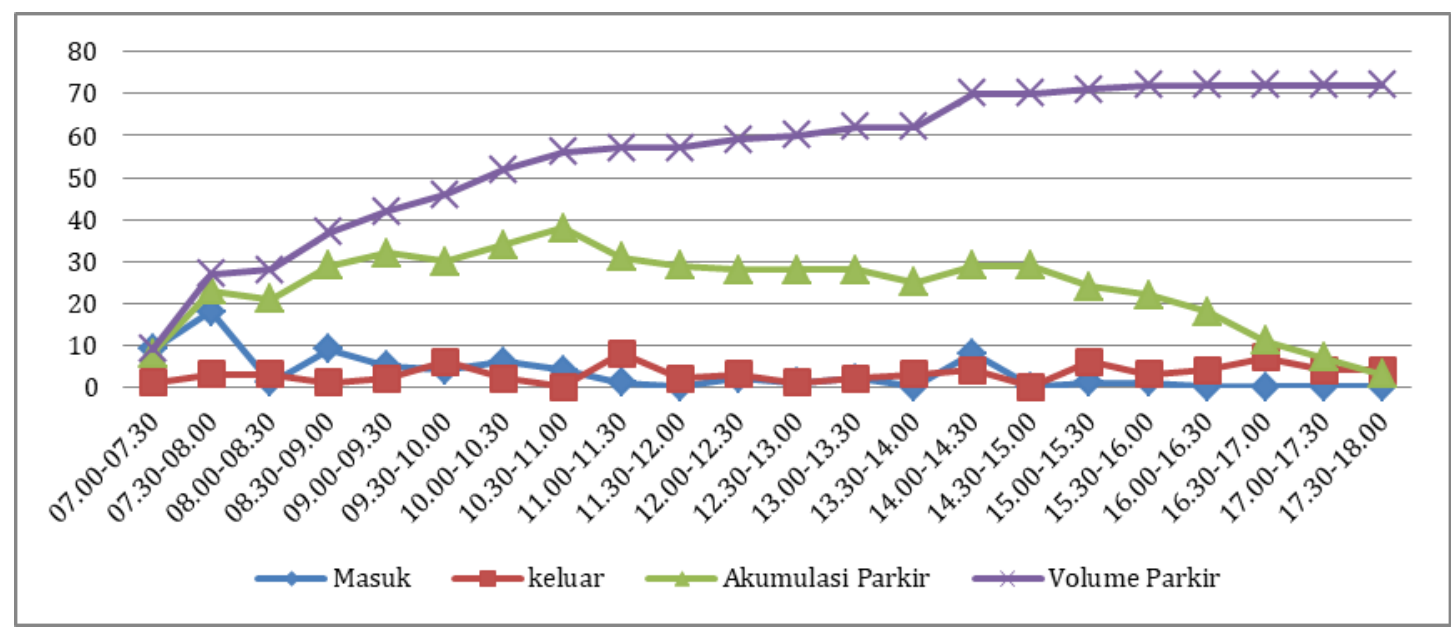

Gambar 7 : Grafik Volume Parkir Mobil dan Akumulasi Parkir di Areal Parkir Kampus II ITP (Asumsi)

\section{Analisis Dampak Lalulintas}

Berdasarkan data yang diperoleh dari Institut Teknologi Padang, bahwa rencana pembangunan gedung di kampus II ITP dilakukan secara bertahap, yaitu :

Tabel 5 : Tahapan Pembangunan Kampus II ITP Padang

\begin{tabular}{|c|l|c|}
\hline No & \multicolumn{1}{|c|}{ Jenis Gedung } & Tahun Pembangunan \\
\hline 1 & Fakultas Vokasi & $2020-2023$ \\
\hline 2 & Rusunawa & 2020 \\
\hline 3 & Convention Center & $2023-2025$ \\
\hline
\end{tabular}

Tahapan pembangunan tersebut akan berpengaruh terhadap kinerja lalulintas pada tahun 2020-2025. Untuk proyeksi tahunan selama masa pembangunan, di asumsikan tingkat pertumbuhan lalulintas adalah $3 \%$ yaitu berdasarkan tingkat pertumbuhan lalulintas di kota Padang, selanjutnya ditambahkan dengan bangkitan/tarikan perjalanan pada masa konstruksi.

Berdasarkan survei, lebar jalur ruas jalan DPR adalah 5 meter dengan tipe jalan 1 lajur 2 arah, sedangkan lebar jalan Bypass adalah 14 meter tipe jalan 4 lajur 2 arah dengan median.

\section{a. Kondisi Pra Konstruksi}

Pada tahap pra konstruksi, gangguan lalulintas pada tahap pra konstruksi dalam kondisi hambatan yang kecil pada Jalan DPR dan Bypass. Rincian kinerja dan gangguan lalulintas pada daerah studi dapat dilihat pada Tabel 6 . 
Tabel 6: Kapasitas Masing-Masing Ruas Jalan

\begin{tabular}{|c|l|c|c|c|c|c|c|c|c|}
\hline \multicolumn{2}{|c|}{ Ruas Jalan } & $\begin{array}{c}\text { W } \\
(\mathbf{m})\end{array}$ & $\begin{array}{c}\text { Wc } \\
(\mathbf{m})\end{array}$ & $\begin{array}{c}\text { Co } \\
(\mathbf{s m p / j a} \\
\mathbf{m})\end{array}$ & FCw & FCsp & FCsf & FCcs & C (smp/jam) \\
\hline 1 & DPR & 5 & 5 & 2.900 & 0,56 & 1 & 0,94 & 1 & $1.526,56$ \\
\hline 2 & $\begin{array}{l}\text { By Pass Arah } \\
\text { Bandara }\end{array}$ & 7.5 & 7,5 & 3.300 & 1,04 & 1 & 1 & 1 & 3.432 \\
\hline 3 & $\begin{array}{l}\text { By Pass Arah } \\
\text { Teluk Bayur }\end{array}$ & 7.5 & 7,5 & 3.300 & 1,04 & 1 & 1 & 1 & 3.432 \\
\hline
\end{tabular}

Tabel 7: V/C Ratio Masing-Masing Ruas Jalan

\begin{tabular}{|c|l|c|c|c|c|}
\hline \multicolumn{2}{|c|}{ Ruas Jalan } & $\begin{array}{c}\text { Kapasistas } \\
\text { (smp/jam) }\end{array}$ & $\begin{array}{c}\text { Volume Tertinggi } \\
\text { (smp/jam) }\end{array}$ & V/C Ratio & $\begin{array}{c}\text { Level of } \\
\text { Service }\end{array}$ \\
\hline 1 & DPR & $1.526,56$ & 514,00 & 0,34 & $\mathrm{~B}$ \\
\hline 2 & $\begin{array}{l}\text { By Pass Arah } \\
\text { Bandara }\end{array}$ & 3.432 & $1.192,10$ & 0,35 & $\mathrm{~B}$ \\
\hline 3 & $\begin{array}{l}\text { By Pass Arah } \\
\text { Teluk Bayur }\end{array}$ & 3.432 & $1.180,35$ & 0,34 & $\mathrm{~B}$ \\
\hline
\end{tabular}

Tabel 8 : Kinerja Ruas Jalan Pra Konstruksi (Tahun 2020)

\begin{tabular}{|c|l|c|c|}
\hline No & \multicolumn{1}{|c|}{ Ruas } & V/C Rasio & Kinerja \\
\hline 1 & DPR & 0,34 & B \\
\hline 2 & By Pass Arah Bandara & 0,35 & B \\
\hline 3 & By Pass Arah Teluk Bayur & 0,34 & B \\
\hline
\end{tabular}

\section{b. Kondisi Masa Konstruksi}

Berdasarkan hasil analisis, bertambahnya volume lalu lintas pada tahap konstruksi karena adanya arus keluar masuk barang/material pada kawasan pembangunan. Hasil perhitungan volume pada saat masa konstruksi dan V/C Ratio Pembangunan Kampus II ITP Padang dapat dilihat pada tabel 9 dan tabel 10.

Tabel 9: Volume Lalulintas Masa Konstruksi Kondisi Tahun 2020-2022

\begin{tabular}{|c|l|c|c|c|}
\hline \multirow{2}{*}{ NO } & \multirow{2}{*}{ RUAS JALAN } & \multicolumn{3}{|c|}{ Volume Masa Konstruksi } \\
\cline { 3 - 5 } & & $\mathbf{2 0 2 0}$ & $\mathbf{2 0 2 1}$ & $\mathbf{2 0 2 2}$ \\
\hline 1 & DPR & 553,00 & 568,42 & 584,30 \\
\hline 2 & By Pass Arah Bandara & 1231,10 & 1266,86 & 1303,70 \\
\hline 3 & By Pass Arah Teluk Bayur & 1219,35 & 1254,76 & 1291,23 \\
\hline
\end{tabular}


Tabel 10 : Kinerja Ruas Jalan Masa Konstruksi (2020-2022)

\begin{tabular}{|c|l|c|c|c|c|}
\hline \multirow{2}{*}{ No } & \multicolumn{2}{|c|}{ Ruas Jalan } & \multirow{2}{*}{ Kapasitas } & \multicolumn{3}{|c|}{ V/C Ratio Masa Konstruksi } \\
\cline { 4 - 6 } & & & $\mathbf{2 0 2 0}$ & $\mathbf{2 0 2 1}$ & $\mathbf{2 0 2 2}$ \\
\hline $\mathbf{1}$ & DPR & $1.526,56$ & 0,36 & 0,37 & 0,38 \\
\hline $\mathbf{2}$ & By Pass Arah Bandara & 3.432 & 0,36 & 0,37 & 0,38 \\
\hline $\mathbf{3}$ & By Pass Arah Teluk Bayur & 3.432 & 0,36 & 0,37 & 0,38 \\
\hline
\end{tabular}

\section{c. Kondisi Pasca Konstruksi 5 Tahun Yang Akan Datang}

Pada masa pasca konstuksi, penambahan volume lalu lintas lebih besar dari pada masa konstruksi dikarenakan pada masa tersebut Kampus II ITP sudah mulai dioperasionalkan sehingga berpengaruh terhadap kinerja ruas jalan. Untuk penambahan volume dilihat pada tabel 12 serta untuk V/C rationya pada tabel 13 .

Tabel 12: Penambahan Mahasiswa

\begin{tabular}{|c|c|c|c|c|c|}
\hline \multirow{2}{*}{$\begin{array}{c}\text { Jenis } \\
\text { Kendaraan }\end{array}$} & $\begin{array}{c}\text { Volume } \\
\text { Kendaraan }\end{array}$ & \multicolumn{2}{|c|}{$\begin{array}{c}\text { Komposisi Jumlah } \\
\text { Mahasiswa }\end{array}$} & \multicolumn{2}{c|}{$\begin{array}{c}\text { Komposisi Jumlah Mahasiswa } \\
\text { Menggunakan Kendaraan }\end{array}$} \\
\cline { 5 - 6 } & & $\begin{array}{c}\text { Vokasi } \\
\text { (D III) }\end{array}$ & SI & $\begin{array}{c}\text { Vokasi } \\
\text { (D III) }\end{array}$ & SI \\
\hline Sepeda Motor & 246 & 360 & 1600 & 45 & 201 \\
\hline Mobil & 38 & $(18.4 \%)$ & $(81.6 \%)$ & 7 & 31 \\
\cline { 5 - 6 }
\end{tabular}

Tabel 13 : Kinerja Ruas Jalan Pasca Konstruksi Gedung Kuliah (tahun 2025)

\begin{tabular}{|c|c|c|c|}
\hline No & Ruas & V/C Rasio & Kinerja \\
\hline 1 & DPR & 0.45 & C \\
\hline 2 & By Pass Arah Bandara & 0.43 & B \\
\hline 3 & By Pass Arah Teluk Bayur & 0.42 & B \\
\hline
\end{tabular}

\section{d. Kebutuhan Ruang Parkir}

Kebutuhan ruang parkir dihitung berdasarkan asumsi jumlah kendaraan kampus I yang diproyeksikan akan pindah ke kampus II (tahun 2025). Berdasarkan proyeksi pertumbuhan kendaraan pada rahun 2025, maka kebutuhan ruang parkir untuk sepeda motor sebanyak 199 SRP dan untuk mobil sebesar 60 SRP, dengan jumlah total 128 SRP. Sedangkan ruang parkir yang direncanakan mencapai 322 ruang parkir meliputi 256 SRP sepeda motor dan 66 SRP untuk mobil. Menurut hasil analisis kebutuhan ruang parkir, jumlah tersebut adalah mencukupi.

Tabel 14 : Proyeksi Kebutuhan Ruang Parkir (tahun 2025)

\begin{tabular}{|c|c|c|c|c|c|c|c|c|}
\hline No & Kendaraan & $\begin{array}{l}\text { Durasi } \\
\text { Parkir } \\
\text { Rerata }\end{array}$ & $\begin{array}{c}\text { Jumlah } \\
\text { Kend. } \\
\text { Parkir }\end{array}$ & $\begin{array}{c}\text { Jumlah } \\
\text { Kend. } \\
\text { Parkir } \\
\text { Vokasi }\end{array}$ & $\begin{array}{c}\text { Jumlah } \\
\text { Kendaraan } \\
\text { Parkir di } \\
\text { GCC }\end{array}$ & $\begin{array}{c}\text { Kebutuha } \\
\text { n Ruang } \\
\text { Parkir }\end{array}$ & $\begin{array}{c}\text { SRP } \\
\text { Yang } \\
\text { Disedia } \\
\text { kan }\end{array}$ & Ket. \\
\hline
\end{tabular}


Wilton Wahab, Afrizal Putra Prices, Angelalia Roza / Jurnal Rab Contruction Research 5 (2) (2020)

\begin{tabular}{|c|c|c|c|c|c|c|c|c|}
\hline & & $($ Jam $)$ & $\begin{array}{c}(\mathrm{kend} / \mathrm{ja} \\
\mathrm{m})\end{array}$ & (kend) & (kend) & SRP & SRP & \\
\hline 1 & $\begin{array}{c}\text { Sepeda } \\
\text { Motor }\end{array}$ & 2,5 & 45 & 113 & 86 & 199 & 256 & Tercukupi \\
\hline 2 & Mobil & 2,6 & 7 & 18 & 42 & 60 & 66 & Tercukupi \\
\hline \multicolumn{2}{|r|}{ JUMLAH } & $\mathbf{2 0 6}$ & $\mathbf{1 3 1}$ & $\mathbf{1 2 8}$ & $\mathbf{2 5 9}$ & $\mathbf{3 2 2}$ & \\
\hline
\end{tabular}

\section{KESIMPULAN DAN SARAN}

Berdasarkan hasil penelitian dapat disimpulkan bahwa kinerja ruas jalan pada saat pra konstruksi dalam kategori baik $(\mathrm{V} / \mathrm{C}$ ratior $=0,35)$, pada masa konstruksi tahun 2022 masih kategori baik $(\mathrm{V} / \mathrm{C}$ ratio $=0,38)$, dan pada masa pasca konstruksi yaitu setelah gedung difungsikan tahun 2025 kinerja ruas jalan DPR masih dalam kategori baik (V/C ratio $=0,42)$ sedangkan ruas jalan Bypass kinerja ruas jalan dalam kategori cukup (V/C ratio $=0,45)$. Hasil penelitian tersebut menunjukkan bahwa dengan adanya pembangunan kampus II ITP tingkat pelayanan (kinerja) ruas jalan masih dalam kategori baik (B), walaupun ada penurunan kinerja ruas jalan Bypass dari kategori baik menjadi cukup, namun secara kinerja masih tergolong baik. Sedangkan proyeksi kebutuhan ruang parkir pada kampus II apabila beroperasi tahun 2025 masih cukup untuk menampung jumlah kendaraan. Adapun saran kepada pengelola ataupun instansi terkait, bahwa sebelum Gedung kampus II ITP mulai beroperasi pada tahun 2025, sebaiknya akses pejalan kaki (trotoar) dan pemasangan rambu-rambu perlu diadakan.

\section{UCAPAN TERIMA KASIH}

Penulis mengucapkan terima kasih kepada segenap pihak yang telah memberikan bantuan sehingga penelitian ini dapat terselenggara dengan baik.

\section{DAFTAR PUSTAKA}

Anonim.1994. Highways and Transportation. The Journal of the Institution of Highways and Transportation \& IHIE. London.

Badan Pusat Statistik. (2019), Jumlah Penduduk dan Luas Wilayah. Kota Padang.

Dikun, S, \& Arief, D. (1993). Strategi Pemecahan Masalah Luas Bangunan dan Lalu Lintas, Bahan Seminar Dampak pemanfaatan Intensitas lahan gedung tinggi / Superblok di Jakarta terhadap lalu lintas disekitarnya. Universitas Taruma Negara bekerja sama dengan Pemerintah DKI Jakarta.

Direktorat Jendral Bina Marga Republik Indonesia. 1997. Manual Kapasitas Jalan Indonesia (MKJI). Departemen Pekerjaan Umum. Jakarta. 
Direktorat Jendral Bina Marga Republik Indonesia. 1995. Tata Cara Perencanaan Fasilitas Pejalan Kaki Di Kawasan Perkotaan. Departemen Pekerjaan Umum. Jakarta.

Firdaus, O. (2017). Analisis Dampak Lalu Lintas (Andalalin) kawasan Kampus Universitas Bangka belitung. Universitas bangka Belitung. ISBN : 978-602-61545-0-7

Jamani, W. Y., Hasyim, \& Rohani. (2016). Analisis Dampak Lalu Lintas (Andalalin) Akibat Pembangunan Rumah Sakit Graha Ultima Medika. Universitas Mataram Mataram. Spektrum Sipil, Vol. 3, No. 1 : 81 - 91, Maret 2016 / ISSN 1858-4896

Undang-Undang No. 22 Tahun 2009 Tentang Lalu Lintas Angkutan Jalan. Jakarta.

Peraturan Pemerintah No. 32 Tahun 2011 Tentang Manajemen dan Rekayasa, Analisa Dampak, Serta Manajemen Kebutuhan Lalu Lintas Jakarta.

Rahman, A., machsus, M., Mawardi, A. F., \& Basuki, R. (2018). Analisis Dampak Lalu Lintas Akibat Pembangunan Apartemen Puncak Dharmahusada Surabaya. Institut Teknologi Sepuluh November Surabaya. Jurnal Aplikasi Teknik Sipil, Volume 16, Nomor 2, Agustus 2018 (69-76)

Rantung, T., Sompie, B. F., \& Jansen, F. (2015). Analisa Dampak Lalu Lintas (Andalalin) Kawasan Lippo Plaza Kairagi Manado. Universitas Sam Ratulangi Manado. Media Engineering Vol.5 No.1, Juni 2015 (315-327) ISSN: 2087-9334

Safitri, R. (2013). Analisa Dampak Lalu Lintas Akibat pembangunan Hartono Lifestyle Mall di Solo Baru. Universitas Sebelas Maret Surakarta.

Safridho, A. Y. (2017). Analisis Dampak Lalu Lintas Akibat Pembangunan Apartemen Bale Hingil. Institut Teknologi Sepuluh November Surabaya.

Santoso, A. A., \& Khar, M. J. (2016). Kajian Dampak Lalu Lintas (Andalalin) Akibat Bangunan Kompleks Perkantoran Provinsi Kalimantan Utara. Universitas Brawijaya Malang.

Saputra, P. A. (2018). Analisis Dampak Lalu Lintas (Andalalin) pada Kawasan Komersil Jalan Ahmad Yani Pekanbaru. Universitas Quality Medan. Juitech / Vol.02 / No. 02 / Oktober 2018 / p-ISSN : 2580-4057 / e-ISSN : 2597-7261

Styawan, A., Cahyo, Y., \& Ridwan, A. (2019). Analisis Dampak Lalu Lintas Revitalisasi Pasar Sumbergempol Kabupaten Tulungagung. Universitas Kediri Kediri. JURMATEKS, Vol. 2, No. 2 Oktober 2019 / e ISSN : 2621-7686

Sumajouw, J., Somple, B. F., \& Timboeleng, J. A. (2013). Analisis Dampak Lalu Lintas (Andalalin) Kawasan Kampus Universitas Sam Ratulangi. Universitas Sam Ratulangi Manado. MEDIA ENGINEERING Vol. 3, No. 2, Juli 2013 ISSN 2087-9334 (133-143)

Tambunan, H. F. (2016). Analisis Dampak Lalu lintas Terhadap Pembangunan Hotel POP. Universitas lampung Bandar Lampung.

Tamin, O. Z. (2000). Perencanaan Permodelan Transportasi. Institut Teknologi Bandung. 
Wilton Wahab, Afrizal Putra Prices, Angelalia Roza / Jurnal Rab Contruction Research 5 (2) (2020)

Wahab, W. (2010).Bahan Ajar Rekayasa Lalu Lintas. Institut Teknologi Padang. 